\title{
Male stalking victimization: prevalence, characteristics and impact
}

\section{Marlene Matos, Andreia Matias \& Mariana Gonçalves}

To cite this article: Marlene Matos, Andreia Matias \& Mariana Gonçalves (2019) Male stalking victimization: prevalence, characteristics and impact, Annals of Medicine, 51:sup1, 188-188, DOI: 10.1080/07853890.2018.1562758

To link to this article: https://doi.org/10.1080/07853890.2018.1562758

\section{Published online: 28 May 2019.}

Submit your article to this journal $₫$

山 Article views: 268

Q View related articles ๘

View Crossmark data $\nearrow$ 
A total of 41 intimate partner violence offenders were evaluate.

Results: The results show us that 21 offenders had a secure attachment and 20 had an insecure attachment (assess the two basic dimensions of individual differences in adult attachment style, namely avoidance and preoccupation). We found a positive association between preoccupation and beliefs about violence, namely minimizing small acts of violence $(r=.55$; $p=.00)$, supporting violence through women's misconduct $(r=.36 ; p=.02)$, supporting violence through family privacy $(r=.41 ; p=.00)$ and the general level of tolerance/acceptance of physical and psychological violence $(r=.48 ; p=.00)$. There is a significant correlation between preoccupation and aggression $(r=.52 ; p=.00)$, specifically anger $(r=.48 ; p=.00)$ and hostility $(r=.44 ; p=.00)$. Finally, we corroborate a relationship between preoccupation and psychopathology: Somatization $(r=.34 ; p=.02)$, interpersonal sensitivity $(r=.40 ; p=.01)$, depression $(r=.44 ; p=.00)$, hostility $(r=.37 ; p=.01)$, phobic anxiety $(r=.49 ; p=.00)$ and psychoticism $(r=.45 ; p=.00)$.

Discussion and conclusions: The data demonstrated that some offenders tends to develop an insecure attachment in their intimate relationships, have an intense concern with relationships and a constant desire of closeness and obsession with abandonment and loss of intimacy. In a global analysis it appears that the attachment is relate with beliefs, aggression and psychopathology. In fact, these results allow aid professionals and institutions to have a deep knowledge about adult attachment as a risk factor.

CONTACT Iris Almeida ialmeida@egasmoniz.edu.pt, iris.egasmoniz@gmail.com

\title{
Reference
}

[1] Roberts N, Noller P. The associations between adult attachment and couple violence: The role of communication patterns and relationship satisfaction. In:Simpson JA, Rholes WA, editors. Attachment theory and close relationships. New York: Guilford; 1998. p. 317-351.

\section{Male stalking victimization: prevalence, characteristics and impact}

\author{
Marlene Matos, Andreia Matias and Mariana Gonçalves \\ Center of Investigation in Psychology, School of Psychology, University of Minho, Braga, Portugal
}

Introduction: Men are more likely than women to engage as perpetrators of violent crime [1]. Male victimization has remained under-researched and only more recently had received scientific interest (e.g., intimate partner victimization) [2]. Likewise, stalking has been characterized by a high number of women involved as victims and men involved as perpetrators [3], being recognized as a gender crime against women in the Istanbul Convention [4]. Research on perceptions of stalking has revealed that male stalking victimization is considered less concerning and less dangerous than female victimization and that males should be able to control their own stalking experience [1]. This study aimed to identify the prevalence, characteristics and impact of stalking victimization in Portuguese men. Helpseeking behaviors are also analyses.

Materials and methods: We used a subsample composed for 570 men, retrieved from of a representative national sample inquired about stalking victimization. The participants were a mean age of $43.78(D P=17.99)$, were mostly married (51\%) and employed (71\%). The Stalking Victimization Inventory was developed to assess stalking victimization and associated features. The inventory included 23 items, organized in five sections, namely sociodemographic characterization, prevalence of stalking victimization, behaviors and dynamics, impact, and helpseeking sources. To guarantee that participants understood the focus of the study, data were collected through face-to-face interviews, conducted all over the country, during three months.

Results: The lifetime prevalence of stalking in men was $13.6 \%(n=$ ?). The stalker was mostly perpetrated by a woman (75\%), without any intimate relationship (former or actual) in $62 \%$ and by an intimate partner in $38 \%$ of the cases. The participants were victims of a diversity of stalking behaviours $(M=3.48 ; D P=2.07)$. For the majority stalking lasted more than a month (71\%) and, in the most intense phase, stalker attacks occurred daily or weekly (86\%). The majority (80.8\%) reported that stalking behaviours negatively affected some area of their individual functioning, with intimate relationships and psychological health being the most affected (57\% and 54\%, respectively). A hierarchical linear regression allowed to identify as significant independent predictors of greater impact the sex of the stalker (being male, $\mathrm{B}=-3.87,95 \% \mathrm{Cl}$ $[-7,15,619])$, a higher diversity of stalking behaviours suffered $(B=.94,95 \% C l[.24,1.63])$ and to feel fear as a consequence of the stalking victimization $(B=7.11,95 \% \mathrm{Cl}[2.68,11.52])$. Despite this, only $25.4 \%$ of the victims sought some kind of support to cope with stalking victimization.

Discussion and conclusions: The results show that stalking against men in Portugal should deserve more attention, namely because it has an impact on different areas and well-being of victims. Victim support institutions and judicial entities should ensure gender neutral support services in order to adequate response to the needs of male victims. 


\title{
References
}

[1] Wigman SA. Male victims of former-intimate stalking: A selected review. International Journal of Men's Health. 2009;8(2):101-115. doi:10.3149/jmh.0802_101

[2] Machado A, Hines D, Matos M. Characteristics of Intimate Partner Violence Victimization Experienced by a Sample of Portuguese Men. Violence and Victims. 2018;33(1):157-175.

[3] Spitzberg BH, Cupach WR, Ciceraro LDL. Sex differences in stalking and obsessive relational intrusion: Two meta-analyses. Partner Abuse. 2010;1:259-285. doi:10.1891/1946-6560.1.3.259

[4] Grangeia H, Santos M. Stalking by Women: Another Side of Gender Violence. In: Gomes S, Duarte V, editors. Female Crime and Delinquency in Portugal. Cham: Palgrave Macmillan; 2008.

\section{Assessment Guideline for Elder Domestic Violence (AGED)}

\author{
Iris Almeida ${ }^{a, b, c, d, e}$, Ricardo Ventura Baúto ${ }^{b, c, d}$, Ana Raquel Gama ${ }^{c, d}$, Ana Ramalho ${ }^{e}$, Joana Costa ${ }^{c, d}$, \\ Maria Belmira Fernandes ${ }^{e}$, Renata Guarda ${ }^{e}$, Jorge Quintas ${ }^{g}$ and Rosa Saavedra ${ }^{f, g}$ \\ ${ }^{a}$ Instituto Universitário Egas Moniz (IUEM), Almada, Portugal; ${ }^{b}$ Centro de Investigação Interdisciplinar Egas Moniz (CiiEM), Almada, \\ Portugal; 'Laboratório de Psicologia Egas Moniz (LabPSI), Almada, Portugal; 'Laboratório de Ciéncias Forenses e Psicológicas Egas \\ Moniz (LCFPEM), Almada, Portugal; ${ }^{\mathrm{e} G a b i n e t e ~ d e ~ I n f o r m a c ̧ a ̃ o ~ e ~ A t e n d i m e n t o ~ a ̀ ~ V i ́ t i m a ~-~ E s p a c ̧ o ~ C i d a d a n i a ~ e ~ J u s t i c ̧ a ~(G I A V ~-~ E g a s ~}$ \\ Moniz/DIAP Lisboa), Lisboa, Portugal; ${ }^{\mathrm{f}}$ Associação Portuguesa de Apoio à Vítima, Porto, Portugal; ${ }^{9}$ Escola de Criminologia da \\ Faculdade de Direito da Universidade do Porto, Porto, Portugal
}

Introduction: Violence against the elderly is a complex multidisciplinary social problem that requires cooperation between institutions and professionals. World Health Organization [1] defines this kind of violence as a single or repeated action, or the absence of an appropriate action, arising in the context of a relationship where there is an expectation of trust that causes suffering or harm to an elderly person. Occurs through several behaviors involving psychological, physical, sexual, financial violence, neglect and self-neglect [2]. In Portugal it is possible to identify a small number of studies about elder abuse, only about general prevalence and about some subtypes of elder abuse [3], but not about risk assessment. According to Portuguese Association for Victims Support, between 2013 and 2015, were recorded 2.063 processes of elderly people were victims of violence [4]. The main goal of this research is to contribute for the definition and prevalence of elder abuse in Portugal, identifying familiar, social and cultural dynamics and develop an integrative risk management protocol that will allow the elder abuse risk assessment.

Materials and methods: In order to assist the victims' support professionals and the criminal justice system have been developed a new risk assessment tool, called "Assessment Guidelines for Elder Domestic Violence" (AGED). This work is organized in 3 phases/studies: Study I. Elderly abuse prevalence, risk, protective and vulnerability factors study, and checklist variables construction; Study II. Retrospective study of the elder abuse cases reported in the victims support organizations and criminal justice system; Study III. Development of the AGED. All ethical principles have been taken due to the sensitive nature of the data involved.

Results: After study 1 and study 2, the results of the development of AGED were composed by five sections/areas: I. Victim's Risk factors; II. Offender's Risk Factors; III. External, Contextual and Relational Risk Factors; IV. Victim/Context Protective Factors; and finally, V. Institutional Risk Factors, if applicable. AGED also contemplates the possibility of the evaluator being able to add other additional factors that they consider necessary, contributing to the effectiveness of the measurement of the level of risk of the victim (low, moderate or high) and critical factors.

Discussion and conclusions: AGED is developed with the main goal to supporting professionals who work in domestic violence. Scientific community make evident the need for an evidence-based, valid, user-friendly risk assessment tool of elder abuse to support the professionals. This study offers the opportunity to provide professionals specific knowledge, skills, competences and a tool, in order to an effective risk assessment and management of elder abuse, contributing to the efforts for protect victims and prevent the occurrence of future cases. 